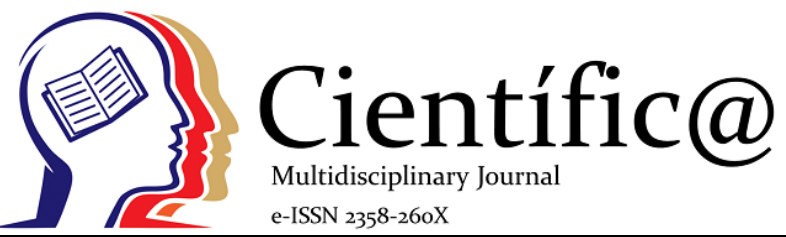

\title{
INVENTÁRIO E PARTILHA: PROCEDIMENTOS EXTRAJUDICIAIS
}

\author{
INVENTORY AND SHARING: EXTRAJUDICIAL PROCEDURES
}

\author{
Leocimar Rodrigues Barbosa ${ }^{1}$, Gleidson Henrique Antunes De Andrade Silva ${ }^{2}$, Rosianny \\ Maria Caetano ${ }^{3}$
}

\begin{abstract}
1 Professor Adjunto da Faculdade Raízes|UniEVANGÉLICA, Mestre em Ciências da Religião PUC-Go.
${ }^{2}$ Professor da Faculdade Evangélica de Goianésia, Mestrando em Ciências Ambientais AEE-Go

${ }^{3}$ Graduada da Faculdade Evangélica Raízes |UniEVANGÉLICA
\end{abstract}

Info

Recebido: 07/10/2019

Publicado: $10 / 02 / 2020$

DOI: $10.29247 / 2358-260 X .2019 v 6 i 2 . p 51-63$

ISSN: 2358-260X

Palavras-Chave
Inventário; Extrajudicial; Procedimentos;
Partilha; Incessante; Sucessão.

Keywords:

Inventory; Extrajudicial; Procedures;

Sharing; Incessant; Succession

\section{Resumo}

O Inventário e a Partilha assumem extrema importância no momento da sucessão, a partir daí, far-se-á o levantamento dos bens que compõem o espólio do "de cujus". Por meio do estudo aprofundado, abordar-se-á assuntos pertinentes ao conhecimento da sociedade, e a demonstração da trajetória jurídica e principalmente extrajudicial. Eis as questões que serão solucionadas detalhadamente no decorrer dos capítulos: Quais são os procedimentos para que o inventário e partilha sejam feitos? Como ocorre a partilha dos bens? Qual é a diferença entre o inventário judicial e o extrajudicial? No presente trabalho, tem-se como objetivo, o desenvolvimento de um estudo minucioso acerca do Inventário e Partilha e seus procedimentos extrajudiciais, abordando cada passo a ser cumprido, dentre outros detalhes, tais como sua relevância social, tendo em vista sua importância e os frequentes casos que surgem de forma cotidiana. Mesmo havendo diversos doutrinadores com grandiosas obras que tratam sobre o tema retro citado, há a necessidade de salientar os benefícios e de forma abrangente, esclarecer todos os meios a serem cumpridos, para que o inventário seja realizado de forma legal, como dispõe o Código Civil. Será feita através do estudo minucioso do tema, a observação e comparação do processo anterior e posterior à vigência da Lei 11.441/2007, quais foram as vantagens, desvantagens e todos os aspectos referentes à lei.

\footnotetext{
Abstract

The Inventory and the Sharing are extremely important at the time of the succession. From there, the assets that make up the "de cujus" estate will be surveyed. Through an in-depth study, it will address issues pertinent to the knowledge of society, and the demonstration of the legal and mainly extrajudicial trajectory. Here are the questions that will be resolved in detail during the chapters: What are the procedures for the inventory and sharing to be done? How does the sharing of assets take place? What is the difference between judicial and extrajudicial inventory? In the present work, the objective is to develop a detailed study about the Inventory and Sharing and its extrajudicial procedures, addressing each step to be accomplished, among other details, such as its social relevance, considering its importance and the frequent cases that arise on a daily basis. Even though there are several indoctrinators with grandiose works that deal with the aforementioned retro theme, there is a need to highlight the benefits and comprehensively, clarify all the means to be fulfilled, so that the inventory is carried out legally, as provided by the Civil Code. It will be made through the detailed study of the theme, the observation and comparison of the process before and after the validity of Law 11.441 / 2007, which were the advantages, disadvantages and all aspects related to the law.
} 


\section{INTRODUÇÃO}

A pesquisa se elucida através da análise da legislação de modo a suprir a dúvida elencada nos problemas a serem solucionados no decorrer dos capítulos. Verificar quais foram as inovações previstas na lei, demonstrando assim as mudanças econômicas, jurídicas, a celeridade e burocracia a ser enfrentada até que o Inventário seja finalizado.

O objetivo principal é contribuir cientificamente e desenvolver a investigação dos pontos relevantes pertinentes às dúvidas que serão sanadas e assim descrever os passos a serem seguidos para o devido cumprimento procedimental do inventário, valendo-se da hipótese de que a partilha seja feita de forma simples, prática e rápida, evitando prejuízos e constrangimentos à família. Estudar a doutrina relacionada ao tema, de modo a entender o objetivo dos autores selecionados e transmitir o conhecimento adquirido por meio do trabalho de conclusão de curso. Discutir a eficácia do Inventário Extrajudicial, que é comumente comparado ao Judicial. Auxiliar os herdeiros ao caminho a ser trilhado para que seja realizado e concluído todo o processo, de forma benéfica. Questionar a vantagem do procedimento notarial, para concluir e verificar a diferença de custas, e o quão hábil se torna, quando realizado desta forma. Esclarecer os problemas encontrados na doutrina, quanto aos riscos na abertura extrajudicial do inventário e partilha dos bens do "de cujus". Apresentar a comparação pelo meio judicial e o retro citado.

As perguntas elencadas no início do presente trabalho serão respondidas através do estudo evidenciado pela incessante pesquisa, pelo teor a ser desenvolvido no decorrer deste.

A primeira delas se refere aos procedimentos para que o inventário e partilha se realizem, fato pelo qual será demonstrado no terceiro capítulo. $\mathrm{O}$ assunto acima mencionado tem sua relevância, por ser a peça central do trabalho.

O segundo quesito a ser esclarecido, é voltado à partilha dos bens, como ocorre, e além do mais, a demonstração dos requisitos para a realização da mesma, detalhadamente será tratado no segundo capítulo.

A terceira pergunta, anteriormente lançada, faz jus à diferença entre o inventário judicial e o extrajudicial, pela importância contida na questão, será analisada com afinco em um dos tópicos mais relevantes, também do segundo capítulo. Faz-se necessário enaltecer que o conhecimento de tal diferenciação é requisito principal para que o inventário se proceda.

Quanto aos materiais utilizados, foi realizada a pesquisa bibliográfica em livros de Direito Civil, que tenham abrangência em Sucessões, de forma especificada. Também utilizar-se-á pesquisa virtual, devido à atualização e quantidade de conteúdos disponíveis.

Os principais autores lidos são Brunno Pandori Giancoli, Carlos Roberto Gonçalves, Armando Rizzardo, Maria Helena Diniz, Orlando Gomes, sendo que são autores que influenciarão de forma intensa as ideias compostas no decorrer do trabalho. A fundamentação será realizada através da Lei de Inventário 11.441/2007.

Far-se-á uma pesquisa histórica, explicativa e bibliográfica. Primeiramente, analisar-se-á o conteúdo histórico do inventário e partilha, como foi seu surgimento, de maneira comparativa à atualidade. Posteriormente haver-se-á a explicação de todos os parâmetros referentes ao tema exposto, esmiuçando as entrelinhas referentes ao conteúdo a ser abordado. E por fim, a compilação da bibliografia a ser pesquisada e os textos virtuais que serão pormenorizados no decorrer do trabalho. 
Pretende-se demonstrar quanto às mudanças relacionadas ao Direito das Sucessões, que influenciam de certo modo, no âmbito social, econômico, e mais adiante efetuar-se-á o questionamento quanto às vantagens e desvantagens do inventário extrajudicial.

\section{O DIREITO DAS SUCESSÕES}

O Direito das Sucessões é a parte especial do Direito Civil que regula a destinação do património de uma pessoa após seu falecimento. (GOMES, 2008, p. 01)

Cabe salientar que, com a morte, há o fim da existência de uma pessoa, e a partir daí surge o direito sucessório daqueles que procedem a sua descendência, pode-se verificar que:

\begin{abstract}
A sucessão, no questionado ramo do direito civil, tem, pois, como pressuposto, do ponto de vista subjetivo, a morte do autor da herança. Antes desse evento, o titular da relação jurídica é o de cujus (abreviatura de expressão de cujus hereditatis agitur). Depois dele, o herdeiro torna-se titular, sucedendo ao defunto, tomando-lhe o lugar e convertendo-se a si no sujeito de todas as relações jurídicas, que a este pertenciam. $\mathrm{O}$ herdeiro substitui, destarte, o falecimento, assumindo-lhes os direitos e obrigações. Em matéria sucessória não vige, portanto, o velho preceito Mors Moniz, solvit. (MONTEIRO, 2009, p. 01)
\end{abstract}

A palavra "suceder" tem o sentido genérico de virem os fatos e fenômenos jurídicos "uns depois dos outros" (sub cedere). É a respectiva sequência. (PEREIRA, 2014, p. 01)

\begin{abstract}
Há autores, como D'Aguano, que procuram justificar o fundamento científico do Direito Sucessório nas conclusões da biologia e da antropologia atinentes ao problema da hereditariedade biopsicológica, segundo a qual os pais transmitem à prole não só os caracteres orgânicos, mas também as qualidades psíquicas, resultando daí que a lei, ao garantir a propriedade pessoal, reconhece que a transmissão hereditária dos bens seja uma continuação biológica e psicológica dos progenitores. (DINIZ, 2014, p. 19)
\end{abstract}

A continuidade é a palavra que define de forma notória, aquilo que ocorre com a abertura da sucessão, é o momento em que se dá a transmissão do patrimônio deixado pelo "de cujus", ou seja, o falecido cujos bens estejam em trâmites de inventário, tal tema será tratado de forma pormenorizada mais adiante.

Todo patrimônio constituído durante a vida, é verificado no momento da abertura da sucessão e transmitido aos herdeiros de forma judicial ou extrajudicial, ou seja, pelo Inventário e a posterior Partilha.

A sucessão pode ocorrer por ato de vontade ou por determinação de lei, podendo ser explicada da seguinte forma:

\begin{abstract}
A sucessio inter vivus, é a causa da transmissão, a vontade humana, emitida de acordo com a lei, há um ato de transferência do titular do direito ou de quem se encontra revestido de legitimidade para dispor do bem; A sucessio causa mortis, é o fenômeno da morte, nas hipóteses legalmente previstas, temse a morte como fator fundamental da transmissão. Ocorrido o óbito, opera-se a separação notória entre a patrimonialidade e a personalidade. (PEREIRA, 2014, p. 01 e p.05)
\end{abstract}

O homem é perseguido pelo estigma de sua finitude. A sucessão é o ato pelo qual uma pessoa toma o lugar de outra e assume os direitos que a esta tocavam. (RIZZARDO, 2014, p.01)

O termo sucessão é empregado de forma restrita, designando apenas a transmissão dos bens de uma pessoa (de cujus) em decorrência de sua morte para outra, também chamado de sucessor. (GIANCOLI, 2012, p. 467)

Há a mudança da pessoa por outra, ou seja, ocorre a transferência dos direitos e obrigações do falecido para os herdeiros.

Para que ocorra a transmissão, há a necessidade de verificar quais os herdeiros vivos e concebidos existentes. A morte real deve ser atestada, a partir da constatação da existência da morte. (LISBOA, 2013, p. 339 e 340$)$

A sucessão é um dos modos de aquisição da propriedade. Os créditos e obrigações passam aos 
sucessores causa mortis. A sucessão legítima descansa no

Direito de Família, e assim por diante. (GOMES, 2008, p. 01)

Para se tratar de Inventário, primeiramente necessita-se entender de que se trata a herança, vê-se:

A herança é, pois, o conjunto de bens, direitos e deveres patrimoniais, ou seja, a universalidade das relações jurídicas de caráter patrimonial em que o falecido era sujeito ativo ou passivo. A herança pode apresentar um caráter positivo ou negativo. Isto é, na compensação do seu ativo e passivo, podemos chegar à conclusão de que o primeiro supera o segundo, havendo superavit, ou que, ao contrário, é por ele ultrapassado, ocorrendo déficit . Tem-se, no primeiro caso, a herança positiva, e, no segundo, a herança negativa, caracterizada pela existência de dívidas superiores aos haveres. (WALD, 2009, p. 02)

O Direito das Sucessões tem fundamentos diversos e o conhecimento da evolução histórica do mesmo, interessa a partir do Direito Romano. (GOMES, 2008, p. 03)

A história das sucessões passou por diversas transformações e através das mesmas, hoje vê-se o Direito das Sucessões como uma lapidação de tudo o que ocorreu no início do ramo.

\begin{abstract}
No Direito das XII Tábuas, o pater famílias tinha absoluta liberdade de dispor dos seus bens para depois da morte, mas, se falecesse sem testamento, a sucessão se devolvia, seguidamente, a três classes de herdeiros: Heredes sui et necessarii, eram os filhos sob patrio poder, a mulher in anu, quia filiae loco est $\mathrm{e}$ outros parentes sujeitos ao de cujus; Agnati, as pessoas sob o mesmo patrio poder ou que a ele se sujeitariam se o pater famílias não estivesse morto. A herança não era deferida a todos os agnados, mas ao próximo no momento da morte; Gentiles, os membros da mesma gens. (GOMES, 2008, p. 03)
\end{abstract}

A modificação da sucessão se deu através de módulos.

Numa estrutura rígida da família, o pater era o soberano. Por testamento, escolhia ele o herdeiro mais habilitado para exercer o comando da família, e realizar as práticas religiosas domésticas, em favor do defunto, além de administrar o patrimônio existente. Conforme ainda, Lacerda de Almeida, "a instituição de herdeiro não tinha outrora, na antiguidade romana, outro intuito mais que escolher ou firmar o continuador na dignidade, autoridade e funções do falecido." (RIZZARDO, 2014, p. 03)

Antes, através do testamento havia a escolha de apenas um dos herdeiros para continuar a administração dos bens deixados. E os outros membros da família eram, de certo modo, subordinados ao escolhido.

Em Roma, numa primeira fase, dizia-se que o herdeiro continuava a personalidade do de cujus, de quem hauria sua forca e coragem. Havia, no começo, mais uma transmissão do ser espiritual do parente falecido. Lacerda de Almeida explicava o direito sucessório: "A necessidade de perpetuar o culto, o nome, as tradições da família, a glória de viver na pessoa do herdeiro. O que se deve ver no testamento como ato de ultima vontade é o pensamento do morto, a sua vontade continuando no herdeiro, vontade morta, incapaz de manifestarse e realizar-se, não fora subsistir no herdeiro, seu continuador, a vida e movimento que se extinguiram no de cujus." (RIZZARDO, 2014, p. 2 e 3)

Verifica-se no pensamento retro citado, a memória do ente querido, na pessoa do herdeiro, que de forma honrosa se recorda em todos os âmbitos do falecido e das vontades que o mesmo possuía. Primeiramente, havia uma comunhão familiar, ou
seja, os bens ficavam com o grupo familiar, já que
persistia a comunidade agrária, sendo as terras de
propriedade coletiva da gens. Isto numa fase
anterior, o que também se verificou em outros
povos. Posteriormente, foram prevalecendo os
sentimentos individualistas, surgindo a propriedade
familiar, um grupo restrito e ligado pelo parentesco
próximo. Transmitia-se a propriedade do varão aos
descendentes, considerados como um pequeno
grupo. Finalmente, firma-se a propriedade
individual, com o arrefecimento dos laços políticos,
religiosos e de parentesco. Opera-se a transmissão
não aos membros da família, mas aos herdeiros,
assim considerados os que estavam submetidos
diretamente à potestade do pai, e aos escravos
instituídos herdeiros por testamento.
(RIZZARDO, 2014, p. 03)

Assim como qualquer lei tem suas alterações, a sucessão também foi instrumento de mudança com o passar do tempo, o modo da transmissão da herança e 
a conceituação dos herdeiros eram tidos de outra maneira. Ressalta-se que havia um entendimento de que a sucessão só ocorria aos herdeiros do sexo masculino e quem recebia os bens, dava continuidade aos desejos do de cujus.

O testamento se expandiu mais na época da Lei das XII Tábuas, quando começaram a perder força os privilégios, e foi se impondo a liberdade absoluta de dispor dos bens para depois da morte. (RIZZARDO, 2014, p. 03)

As leis anteriores propunham que determinados herdeiros fossem melhores sucedidos que outros, porém, logo em seguida, surgiram os testamentos, pelo qual atesta-se a vontade do indivíduo.

Teve grande preponderância o testamento no Direito Romano, o que representava um forte individualismo, em contraposição com o Direito germânico, onde praticamente se desconhecia a sucessão testamentaria. Todavia, diante dos muitos abusos no direito de testar, relata Jefferson Daibert que "na defesa e preservação da própria família, o Direito romano, copiando o Direito grego, estabeleceu uma primeira restrição, um primeiro limite à liberdade de testar. Era uma quarta parte que deveria ser reservada aos parentes próximos do testador... Justiniano elevou aquela parte, chamada legítima, a um terço da sucessão, quando o sucessor tivesse quatro filhos, e à metade se tivesse mais de quatro filhos. Era a garantia e preservação do patrimônio em benefício da família". (RIZZARDO, 2014, p. 04)

Tenta-se de forma individualista preservar o patrimônio para beneficiar os bens da família.

No Direito Germânico, primitivamente os bens permaneciam na sua totalidade com a família. Eram propriedade de seus membros, pois forte o vinculo que os unia, com o que não era aceita a sucessão testamentária, quando foi se impondo a propriedade individual. Em todos os povos primitivos, de modo geral, havia características comuns: os direitos patrimoniais não se partilhavam, mas pertenciam à família. Com a morte do pai, a administração passava ao filho primogênito sempre do sexo masculino. E nestes sistemas (em que só o filho primogênito herdava), ficava o patrimônio nas mãos de um ramo familiar. O primogênito tornava-se opulento. Os demais filhos trabalhavam para aquele, a quem ficavam subordinados, e numa situação econômica inferior. A Bíblia traz exemplos de privilégios em favor da primogenitura. Nos povos em que a sucessão se restringia à linha masculina, não havendo filho, adotava-se um herdeiro, que recebia o encargo de dirigir as práticas religiosas. (RIZZARDO, 2014, p. 05)

Conforme trecho supracitado, com o falecimento do de cujus, a herança era destinada ao primogênito, que tinha o papel de administrar e gerir os bens deixados, e os demais herdeiros deveriam respeito e subordinação ao escolhido.

\section{O INVENTÁRIO E A PARTILHA DOS BENS}

O inventário é realizado para que sejam descritos e avaliados os bens, para que sejam divididos entre os herdeiros, através da partilha.

O inventário é o procedimento pelo qual se define quais bens integram o acervo hereditário e qual quinhão pertencerá a cada herdeiro. Assim, o inventário é a simples enumeração e descrição dos bens e das obrigações que integram a herança. Todos os direitos, bens e obrigações serão incluídos no inventário, integrando o monte-mor. Depois, separar-se-á o que pertencia ao de cujus e distribuirá entre os herdeiros, separando aquilo que pertence ao cônjuge supérstite. Sendo assim, inventário é a descrição minuciosa de todos os bens, obrigações e dívidas ativas deixadas pelo de cujus. É o procedimento de jurisdição contenciosa que discriminará os bens pertencentes ao acervo hereditário e indicará os herdeiros e legatários do de cujus, estabelecendo o quinhão pertencente a cada um. (GONÇALVES, 2009)

É de suma importância saber que, as dívidas do de cujus, também podem ser objeto do inventário, neste momento, será realizado o cálculo da herança líquida, ou seja, qual é o valor ou quais bens cada herdeiro receberá, é o momento em que ocorre a materialização.

As finalidades do inventário são: isolar bens da meação do cônjuge, observar se a herança é suficiente para o pagamento de dívidas, definir pagamento, dispor sobre a realização da partilha, dentre outras. (GONÇALVES, 2009)

É no próprio inventário, que é feita a apuração de cada item citado no parágrafo anterior. 
Com a abertura da sucessão, a herança transmitese, desde logo, aos herdeiros legítimos e testamentários, malgrado os bens imóveis permaneçam ainda em nome do de cujus no Registro de Imóveis. É necessário, então, proceder-se ao inventário, isto é, à relação, descrição e avaliação dos bens deixados, e à subsequente partilha, expedindo-se o respectivo formal. (GONÇALVES, Carlos Roberto, 2017, p. 489)

A forma correta, segundo a legislação, de se fazer a divisão da herança é inicialmente, através do inventário, e assim que o mesmo estiver concluído, deve-se proceder a partilha.

\begin{abstract}
A palavra "inventário" deriva do latim inventarim, de invenire, que significa achar, encontrar, sendo empregada no sentido de relacionar, descrever, enumerar, catalogar o que for encontrado, pertencente ao morto, para ser atribuído aos seus sucessores. Embora os herdeiros adquiram a propriedade desde a abertura da sucessão, os seus nomes passam a figurar no Registro de Imóveis somente após o registro do formal de partilha. Tal registro é necessário para manter a continuidade exigida pela Lei dos Registros Públicos, Lei n. 6.015, de 31-12-1973, art. 195. (GONÇALVES, 2017, p. 489)
\end{abstract}

A partilha é o meio pelo qual os bens passarão ao nome dos devidos herdeiros.

\section{Inventário Extrajudicial}

Com o advento da Lei 11.441 de 04 de Janeiro de 2007, a burocracia que havia para a realização do inventário foi a certo modo, cessada. Importante lembrar que, mesmo que a pessoa tenha falecido antes da vigência da lei, ainda assim, poderá ser feito o inventário através de escritura pública, em um cartório de Notas. bens; que as partes estejam assistidas por advogado. (GOMES, 2008, p. 277)

Tal ato é celebrado de tal maneira:

Celebram-se tais atos através de escritura pública, perante o Tabelionato que as partes envolvidas elegerem, que deverá ser um daqueles onde se deu a abertura da sucessão, ou seja, o do último domicílio do de cujus, em face do Artigo 1.785 do Código Civil. (RIZZARDO, 2014, p. 752)

Caso no domicílio do de cujus haja vários cartórios, as partes decidirão em qual será lavrada a escritura, conforme lhes convier.

\begin{abstract}
A citada lei $\mathrm{n}^{\circ} 11.441$ autorizou a realização de inventário, partilha, separação consensual e divórcio consensual pela via administrativa. Restritamente ao inventário, finalmente permitiu que se faça extrajudicial ou administrativamente, sem a necessidade do referendo judicial, acatandose uma tendência que já era defendida desde o começo da vigência do Código Civil anterior. Parte considerável da doutrina sempre propugnou pela dispensa da via judicial, mas encontrava oposição especialmente de órgãos de advogados, por motivos ligados à atividade profissional, que ficaria reduzida se não admitida a participação do advogado. No entanto, a sua presença é exigida no parágrafo único do Art. 982, fator que afastou ou diluiu as resistências: "O tabelião somente lavrará a escritura pública se todas as partes interessadas estiverem assistidas por advogado comum ou advogado de cada uma delas, cuja qualificação e assinatura, constarão no ato notarial." (RIZZARDO, 2009, p. 589)
\end{abstract}

O inventário passou a ser um procedimento amplo, ou seja, pode ser feito judicialmente e também no âmbito extrajudicial.

Ressalte-se que o inventário e partilha por escritura pública são facultativos. A possibilidade de partilha por meio do denominado "inventário extrajudicial" segue uma tendência moderna admitida em vários países, excluindo da apreciação pelo Poder Judiciário, questões que versem sobre direitos disponíveis entre pessoas maiores e capazes. O texto legal é omisso e sua redação propicia controvérsias, sendo certo que dependerá de regulamentação pelas Corregedorias dos Tribunais de Justiça estaduais, inclusive declarar as funções e responsabilidade do Notário e do Registrador. (GOMES, 2008, p. 277)
Inovou o legislador através da Lei 11.141, de 4 de janeiro de 2006, que deu nova redação ao artigo 983 do Código Civil, permitindo que o inventário e a partilha fossem feitos através de escritura pública, desde que estivessem presentes os seguintes requisitos: o autor da herança tenha falecido $a b$ intestato; os herdeiros sejam maiores e capazes; os herdeiros estejam acordes quanto à divisão dos 
Conforme se verifica na citação acima, as Corregedorias dos Tribunais de Justiça dos estados que regulamentam quanto ao bom e correto funcionamento dos órgãos cartorários.

A adjudicação também é um quesito que pode se realizar por meio de uma escritura, vê-se:

\begin{abstract}
Embora o legislador tenha se referido exclusivamente à partilha, é óbvio que, havendo um só herdeiro, a adjudicação poderá ser objeto de escritura pública. Ainda que o herdeiro seja incapaz, a adjudicação poderá ser feita por escritura pública, pois, nesse caso, não haverá risco de prejuízo, eis que se trata do único beneficiário do acervo hereditário. $\mathrm{O}$ incapaz será representado ou assistido por seu representante legal. (GOMES, 2008, p. 277)
\end{abstract}

A lei proíbe a participação de incapazes somente nos casos de partilha, pois os mesmos poderiam ser prejudicados na divisão dos bens, o que não ocorre no caso de adjudicação. A escritura pública deverá conter a declaração de herdeiros e bens.

Os valores declarados são fiscalizados pela Secretaria da Fazenda e demais órgãos, devido aos impostos que são pagos e para que não haja sonegação.

Com os valores atribuídos pelos herdeiros, sujeitos a posterior verificação pela Fazenda Estadual, os bens serão partilhados da forma que melhor lhes convier, sujeitando-se aos impostos decorrentes da divisão proposta. Os herdeiros que desejarem poderão renunciar à herança ou cedê-la gratuita ou onerosamente a terceiros, que comparecerão à escritura na qualidade de cessionários. (GOMES, 2008, p. 277)

A partilha realizar-se-á conforme a proposta feita pelos devidos herdeiros, e quanto à disponibilidade de cada, para efetuar o pagamento dos impostos da parte que lhes são cabidas.

A lei que regulará a capacidade para suceder é a que estiver em vigor na data da abertura da sucessão, independente da data em que for lavrada a escritura, o que deverá ser verificado pelo Tabelião. (GOMES, 2008, p.278)
Ao efetuar a abertura da sucessão, o próprio Tabelião deverá ser atentar quanto às leis vigentes, para que não ocorra equívocos e ocorra a anulação do ato.

Diferentemente do inventário judicial, quando realizado através de escritura pública, dispensa-se denominado inventariante, de modo específico, pois, ocorrer-se-á apenas a nomeação de um dos herdeiros, para, a certo modo, manter-se atento acerca dos procedimentos que serão realizados. Pode-se analisar:

\begin{abstract}
No inventário extrajudicial, em princípio, não haverá a figura do inventariante, cuja nomeação compete ao Juiz. Os herdeiros poderão eleger um dentre eles para representar o espólio ativa ou passivamente nas ações propostas e, também, para dar cumprimento às obrigações deixadas pelo de cujus. (GOMES, 2008, p. 278)
\end{abstract}

A escritura é um documento público que possui fé pública, é um termo lavrado nos termos da lei, tem a finalidade de prova quanto à propriedade de determinado bem.

\begin{abstract}
A escritura servirá de título para provar, onde for necessária, a nomeação do representante. Qualquer erro cometido na escritura ou ocorrendo exigência procedente do Registro Geral de Imóveis, o ato notarial deverá ser rerratificado por outra escritura para as devidas correções. (GOMES, 2008, p. 278)
\end{abstract}

Caso haja equívocos na lavratura da escritura, o ato deverá ser feito novamente, pelo qual, será lavrada nova escritura, para efetuar as devidas correções.

Os bens que não forem incluídos na escritura poderão ser objeto de sobrepartilha, que deverá ser através de nova escritura. A escritura constitui título hábil para transferência dos imóveis perante o Registro Geral de imóveis e, também para transferência dos bens móveis, embora nesse caso a lei seja omissa. (GOMES, 2008, p.278)

Caso surjam bens após a lavratura da mesma, será feita nova escritura, conceituada como sobrepartilha, como se verifica acima. 


\section{PROCEDIMENTOS DO ARROLAMENTO, INVENTÁRIO PELA VIA ADMINISTRATIVA OU EXTRAJUDICIAL}

\author{
Segundo Diniz (2014, p. 433) “arrolamento é
} um processo de inventário simplificado, caracterizado pela redução de atos formais ou de solenidades".

Arrolar é o mesmo que juntar, demarcar, fazer uma relação do que deve ser realizado. Veja-se o conceito do termo tratado:

\begin{abstract}
O próprio termo 'arrolamento' induz o significado: inscrever numa lista, fazer revelação de, ou, mais especificamente, a ato de colocar em rol de, ou numa relação, tudo em determinada ordem; ou, mais completamente, o ato de dar um ordenamento às coisas ou aos bens. De um lado, conforme já foi longamente examinado, há o inventário procedimento contencioso e desenvolvido num encadeamento de atos sucessivos; e, de outro, o arrolamento, quando então se descreve tudo o que existe e delineia-se a destinação dos bens. Numa concepção técnica, tem-se o inventário quando se faz a descrição completa e individualizada de todo o acervo, isto é, dos bens, das obrigações e dos herdeiros que ficam com a morte de uma pessoa. Mas não se esgota aí o processamento, seguindo-se outros atos, , como a ouvida dos interessados, a avaliação, os cálculos, os pagamentos de obrigações e tributos etc., até chegar-se à partilha, objetivo e etapa final do inventário. Tem-se, ainda, o arrolamento, onde quase insignificante é a atuação do Judiciário, visto que as partes envolvidas trazem a destinação do acervo já definida, inclusive com o pagamento de tributos. (RIZZARDO, 2009, p. 765)
\end{abstract}

Vê-se diante da pesquisa que se elucida, que o arrolamento é uma forma de agilizar o procedimento de inventário.

\footnotetext{
O processo de inventário pode processar-se por via de arrolamento em dois casos. Primeiramente, se a herança for de pequeno porte, é o chamado arrolamento comum. Em segundo lugar, se todos os herdeiros forem capazes e o processo for amigável, neste caso, depara-se com o arrolamento sumário. (FIUZA, 2014, p. 1314)
}

Há modos de simplificar o processo, nos casos em que o patrimônio é pequeno e não há necessidade de demasiadas formalidades, como se pode observar:
Nas heranças de pequeno porte, o processo é simplificado, com a eliminação de termos e formalidades. O inventariante já apresenta a relação dos bens e sua estimativa, que será adotada para sofrer a incidência do imposto de transmissão mortis causa, salvo impugnação fundada de seus valores. A partilha será efetuada em audiência designada pelo juiz, com a presença dos interessados, e decisão, de plano, das pretensões e das questões então levantadas verbalmente ou por escrito. (PEREIRA, 2014, p. 362)

Adiante ser-se-á demonstrado quanto ao procedimento a se realizar, conforme abaixo de enumera:

\begin{abstract}
Uma inicial é dirigida ao juiz, com a descrição do inventariado, dos herdeiros e dos bens, apontando quem exercerá o cargo de inventariante, e mais o pedido de homologação daquilo que decidirem os herdeiros. No âmbito do arrolamento, encontramse duas formas procedimentais. Na primeira arrolamento sumário -, não importa o valor do patrimônio que ficou, mas há um acordo de todos os herdeiros no modo de se partilhar. Na segunda - arrolamento comum -, os bens não ultrapassam a duas mil Obrigações do Tesouro Nacional (OTNs), devidamente atualizadas até a sua extinção e, após, por outros índices que seguiram. (RIZZARDO, 2009, p. 765)
\end{abstract}

Faz-se necessário entender quanto aos tipos de arrolamento e quanto à necessidade de se distinguir ambos, para que não restem dúvidas acerca do tema.

A distinção do arrolamento aqui tratado daquele que figura como medida cautelar, também denominado arrolamento de bens, e admitido nas situações de perigo de danos ou lesão nos bens. Esta espécie não tem pertinência com o inventário ou arrolamento por morte de uma pessoa, e justifica-se tal medida quando da separação judicial e da dissolução de uma sociedade mercantil, dentre outras hipóteses mais raras. Em caso de morte, admite-se para fazer prova da existência do patrimônio, a fim de evitar possível desbaratamento ou alienação por algum herdeiro. (RIZZARDO, 2009, p. 766)

Como dito anteriormente, o arrolamento é uma maneira de apressurar o processo de inventário, fazer com que todo o procedimento seja feito de modo rápido e prático.

O inventário poderá ter seu procedimento simplificado, com a redução de formalidades, 
promovendo-se sob o rito de arrolamento em duas hipóteses expressamente previstas em lei. (CAHALI; HIRONAKA, 2003, p. 466)

\subsection{Do inventário e partilha extrajudicial}

O objeto principal de estudo deste trabalho é o inventário no âmbito extrajudicial, pelo qual, se abrilhanta com o tema, que, notoriamente é tido como peça central do presente capítulo, vê-se:

Para que se aplique o regime notarial na sucessão causa mortis, será preciso que: a) todos os interessados sejam maiores e capazes ou emancipados; a análise da incapacidade far-se-á no momento da escritura. Urge lembrar que, se o de cujus deixou viúva grávida, não se poderá efetuar o inventário extrajudicial. Se um herdeiro for analfabeto, nenhum empecilho haverá, pois poderá fazer uso de impressão digital e assinatura a rogo; b) a sucessão seja legítima, pois o de cujus não pode ter deixado testamento contendo disposições de ordem patrimonial. Logo, nada obsta a que o inventário se dê administrativamente, se o testamento por ele feito contiver disposições pessoas, p. ex., emancipação de filho; reconhecimento de prole ou de união a filho, que no momento do óbito premorreu ou atingiu a maioridade, ou de bem de família convencional; revogação de testamento anterior, para que sejam aplicáveis as normas da sucessão legítima. O notário deve verificar existência, ou não, do testamento, consultando o Registro Central de Testamentos e pedindo certidão do colégio notarial, comprovando inexistência do ato de última vontade. Se houver testamento com conteúdo patrimonial, pode-se fazer partilha por escritura pública se herdeiros forem capazes, seguida de homologação judicial; c) partilha de todos os bens do autor successionis, estando os herdeiros concordes e unânimes. Se for um o herdeiro, não haverá partilha, mas adjudicação dos bens deixados pelo de cujus. É preciso lembrar que há corrente doutrinária admitindo partilha parcial de bens e sobrepartilha extrajudicial; d) comparecimento de todos os interessados perante $o$ tabelião, assistidos por advogado comum ou não, ou por defensor público, cuja qualificação e assinatura constatarão do ato notarial; e) pagamento dos tributos, a que o notário deverá ficar atento, por ser obrigação sua não só a fiscalização de pagamento de impostos que incidirem sobre atos que redigir. Deverá o notário mencionar na escritura a prova da quitação e exigir certidão negativa de tributos, deverão partir para o inventário judicial, requerendo alvará para venda de bem do espólio para pagá-los, Herdeiros poderão pedir alvará para levantar numerário, solver tributos e depois pleitear inventário extrajudicial. (DINIZ, 2014, p. 437)
São inúmeros doutrinadores que tratam do tema, e como parâmetro principal tem-se a lei abaixo mencionada:

Conforme visto no capítulo anterior, com a Lei $n^{\circ}$ 11.441, de 4 de Janeiro de 2007, além de outras alterações, vieram introduzidas no cenário jurídico nacional as vias administrativas ou extrajudiciais de inventário e partilha, de separação e divórcio consensuais. (RIZZARDO, 2009, p. 778)

No inventário extrajudicial, não há a necessidade de homologação judicial, esse é o ponto mais saliente da lei. Persiste a necessidade de inventário judicial se houver testamento ou interessado incapaz. (VENOSA, 2014, p. 90, 91)

O inventário extrajudicial tem a finalidade de se definir os bens deixados pelo falecido, quanto às dívidas a serem pagas e através dele, é realizada a partilha, momento pelo qual, cada herdeiro recebe seus bens. Faz-se necessário elucidar quanto à escritura pública, que poderá por meio de uma minuta, especificando todo o conteúdo a ser explorado, analise-se:

Do conteúdo do preceito extrai-se que serão realizados o inventário e partilha por meio de escritura pública, importando se inventariarem e se repartirem os bens. Pelo inventário, descrevem-se o elenco dos herdeiros ou interessados, com a devida qualificação, e o patrimônio existente, com as onerações ou encargos incidentes, não se afastando a referência das obrigações pendentes, com a forma de seu pagamento. Em relação à partilha, apresenta-se a repartição do patrimônio entre os herdeiros ou interessados, inclusive com a menção da parte que é do cônjuge sobrevivente, se for o caso. Em uma minuta, colocam-se todos os dados necessários, inclusive quanto ao de cujus, instruindo-a com os documentos necessários, relativamente à pessoa falecida, às procurações fiscais, às obrigações, às cessões (se existirem), às colações e à expressa concordância em todos os elementos e na partilha. As partes (herdeiros e outros interessados) serão assistidas por advogado comum ou individual. No entanto, não se torna imprescindível o instrumento de mandato, já que a obrigatoriedade é que se assinale no ato a sua presença, com a menção das pessoas assistidas ou acompanhadas. (RIZZARDO, 2009, p. 779) 
Anteriormente, podia se verificar a diferença quantos aos itens exigidos para a realização do inventário extrajudicial, atualmente foram acrescentados mais quesitos, demonstra-se a seguir:

No Direito Romano admitia-se o inventário extrajudicial, se não houvesse disputa entre os herdeiros. Hoje, só se admite se os herdeiros forem capazes e concordes, e não houver testamento. (FIUZA, 2014, p. 1309)

Para que o inventário seja na via administrativa, tem-se como requisito que todos os herdeiros sejam capazes e estar em concordância, sem qualquer tipo de conflitos. Além do mais, a morte do de cujus será narrada na escritura pública, e o mesmo será qualificado, juntamente coma qualificação dos próprios herdeiros e a especificação de cada bem.

\begin{abstract}
Naturalmente, todos os interessados devem ser capazes e estar concordes, não podendo haver qualquer divergência, e nem faltar qualquer dos herdeiros ou titular de direitos na sucessão. Eventual divergência, e nem faltar qualquer dos herdeiros ou titular de direitos na sucessão. Eventual divergência, ou dúvida sobre o patrimônio, ou discordância relativamente à avaliação para fins de partilha ou de incidência de tributos, conduz à via judicial, porquanto, não se atribui ao tabelião qualquer competência para dirimir conflitos. Deverão, então, os interessados ingressarem com o pedido de abertura de inventário, com todas as decorrências próprias de um processo litigioso. No ato da escritura pública, constarão os elementos constantes da minuta, se houver, ou a descrição dos fatos que compreendem a morte do de cujus e a sua qualificação, os herdeiros e interessados, o patrimônio, a estimativa econômica, a situação fiscal e outros eventos pertinentes. (RIZZARDO, 2009, p. 779)
\end{abstract}

Acerca da necessidade de acompanhamento de advogado, é válido salientar que é indispensável à continuação do procedimento, pode-se verificar:

Os interessados, qualificados devidamente, deverão estar, como já foi dito, assistidos por advogado comum ou advogados de cada um, cuja qualificação completa e assinatura constarão do ato notarial, uma vez que dele participam tecnicamente como assistentes, constituindo sua presença uma exigência legal, dispensando-se a procuração, na lavratura da escritura, da qual constará seu nome e registro na $\mathrm{OAB}$. A presença do advogado será de grande valia para o notário, auxiliando-o na aferição da obediência aos requisitos legais, na conformação dos interesses dos herdeiros às normas de ordem pública etc., e para os interessados, ajudando-os, p.ex., na divisão da herança, dando-lhes mais segurança, na renúncia de herança, ou na cessão de direitos hereditários, pois estas poderão, como ensina Paulo Nader, constar na escritura pública, onde se formalizarão o inventário e a partilha pelos demais herdeiros etc. Se os interessados não tiverem condições econômicas para contratar advogado, o tabelião, pelas razões acima especificadas, deverá recomendar a defensoria pública, onde houver, ou a Seccional da OAB, e, então, deverá constar do ato notarial a qualificação e assinatura do defensor público. Admitem-se inventário e partilha extrajudiciais com viúvo(a) ou herdeiro(s) capazes, inclusive por emancipação, representado(s) por procuração formalizada por instrumento público com poderes especiais, vedada a acumulação de funções de mandatário e de assistente das partes. (DINIZ, 2014, p. 438 e 439)

Caso as partes não nomearem advogado, por falta de condições, será nomeado advogado dativo.

Quanto à presença de advogado, se as partes não dispuserem de condições para a contratação, recomendará o tabelião que se socorram da Defensoria Pública, onde houver, ou na falta, a Seccional da Ordem dos Advogados do Brasil. É obrigatória a nomeação de interessado, na escritura pública de inventário e partilha, para representar o espólio, com poderes de inventariante, no cumprimento de obrigações ativas ou passivas pendentes. (RIZZARDO, 2009, p. 780)

Conforme visto no parágrafo acima, faz-se necessário a nomeação de inventariante para dirimir quanto às obrigações, pois:

A inventariança é encargo pessoal, pois gera responsabilidade própria daquele que a exerce, e de investidura isolada, não podendo ser exercida conjuntamente por duas ou mais pessoas, mesmo que no inventário se tenha mais de um espólio. (DINIZ, 2014, p. 415)

E além de tal fato, podem-se emancipar incapazes, através de procuração pública para o procedimento de inventário, leia-se a seguir:

\footnotetext{
Admitem-se o inventário e a partilha extrajudiciais com viúvo(a) ou herdeiro(s) capazes, inclusive por emancipação, representado(s) por procuração formalizada por instrumento público com poderes especiais, vedada a acumulação de funções de mandatário e de assistente das partes. (RIZZARDO, 2009, p. 780)
} 
Ainda acerca da nomeação de inventariante na escritura, salienta-se a autora a seguir:

Será obrigatória a nomeação do interessado, na escritura pública de inventário e partilha, para representar o espólio, com poderes de inventariante, no cumprimento de obrigações ativas ou passivas pendentes. (DINIZ, 2014, p. 44)

Quanto à retificação da escritura pública de inventário e partilha e as informações nela existentes referentes à qualificação das partes, há que se observar adiante. A escritura pública poderá ser corrigida, desde que todos os herdeiros estejam em comum acordo.

É permitida a retificação da escritura pública, desde que haja o consentimento de todos os interessados. Os erros materiais poderão ser corrigidos de ofício ou mediante ato notarial ou não havendo espaço por escrituração própria, lançada no livro das escrituras públicas e anotações remissivas. $\mathrm{O}(\mathrm{A})$ companheiro(a) pode promover $\mathrm{O}$ inventário e partilha extrajudicialmente, desde que todos os herdeiros e interessados estejam de acordo e, no caso de inexistir outro sucessor, apresentar decisão judicial reconhecendo a união estável e o direito à participação. As partes e respectivos dos cônjuges devem estar, na escritura, nomeados e qualificados (nacionalidade; profissão; idade; estado civil; regime de bens; data do casamento; pacto antenupcial e seu registro imobiliário, se houver; número do documento de identidade; número de inscrição no CPF; domicílio e residência. A escritura pública de inventário e partilha conterá a qualificação completa do autor da herança; o regime de bens do casamento; pacto antenupcial e seu registro imobiliário, se houver; dia e lugar em que faleceu o autor da herança; data da expedição da certidão de óbito; e a menção ou declaração dos herdeiros de que $\mathrm{o}$ autor da herança não deixou testamento $\mathrm{e}$ outros herdeiros, sob as penas da lei. (RIZZARDO, 2009 , p. 780 e 781 )

Enaltece-se que a via notarial é facultativa, podendo os herdeiros sempre optar pelo procedimento judicial. Caso seja por escritura, a mesma será título hábil para a transferência junto ao órgão registral do denominado bem. (FIUZA, 2014, p. 1314)

Para a lavratura da escritura de inventário, necessária se faz a apresentação dos seguintes documentos:
Apresentam-se os seguintes documentos, no original ou em cópia autenticada, exceto os das identidades que sempre serão originais, quando do encaminhamento do inventário e partilha, com a expressão menção na escritura pública: a)certidão de óbito do autor da herança; b) documento de identidade oficial e CPF das partes e do autor da herança; c)certidão comprobatória do vínculo e do parentesco dos herdeiros; c) certidão de casamento do cônjuge sobrevivente e dos herdeiros casados e pacto antenupcial, se houver; e)certidão de propriedade de bens imóveis e direitos a eles relativos; f)documentos necessários à comprovação da titularidade dos bens móveis e direitos, se houver; g)certidão negativa de tributos; e h) Certificado de Cadastro de Imóvel Rural - CCIR, se houver imóvel rural a ser partilhado. O tabelião deverá se atentar quanto à possibilidade de lavrarse a escritura pública a qualquer tempo, cabendo a ele, fiscalizar o recolhimento de eventual multa, conforme previsão em legislação tributária estadual e distrital específica. E o tabelião poderá se negar à lavratura da escritura de inventário ou partilha, se houver fundados indícios de fraude ou em caso de dúvidas sobre a declaração de vontade de algum dos herdeiros, fundamentando a recusa por escrito. (RIZZARDO, 2009, p. 781)

\section{É de grande importância enaltecer acerca da} responsabilidade civil dos atos praticados pelo tabelião, como abaixo se descreve:

\begin{abstract}
O notário, é preciso ressaltar, terá pelos seus atos responsabilidade civil subjetiva, se culposamente causarem dano ao interessado no inventário. Contudo, tal responsabilidade excluída estará, havendo culpa da vítima, culpa de terceiro, força maior ou caso fortuito. Responderá, p. ex., pela não fiscalização de tributos; por erro de dados (CPF, RG, descrição de imóveis, etc.), hipótese em que deverá efetuar escritura de retificação; nulidade de escritura pública. Tal responsabilidade será sempre pessoal, visto que um notário não responde por falha de seu antecessor. Além disso, poderá haver responsabilidade civil objeto do Estado, em razão da escolha do oficial da serventia por ele feita. O prejudicado, portanto, poderá optar por acionar qualquer deles (o notário ou poder estatal) para fazer valer seu direito e obter a reparação do dano, que lhe foi causado. (DINIZ, 2014, p. 443)
\end{abstract}

Quando houver apenas um herdeiro, ocorrerá da seguinte maneira e ainda, caso haja cobrança ou execução, recair-se-á sobre os bens:

$\mathrm{Na}$ existência de um único herdeiro, maior e capaz, com direito à totalidade da herança, não haverá partilha, lavrando-se a escritura de inventário e adjudicação dos bens. A existência de credores do espólio não impedirá o inventário e a partilha, ou adjudicação, por escritura pública. Evidente que 
qualquer execução ou cobrança se faz nos bens inventariados e partilhados. (RIZZARDO, 2009, p 781)

Seguidos todos os procedimentos acima mencionados, ocorrer-se-á o inventário extrajudicial, como dito anteriormente, procedimento criado para desburocratizar o cotidiano dos herdeiros e/ou sucessores.

\section{CONSIDERAÇÕES FINAIS}

O trabalho foi extremamente proveitoso, quanto ao conhecimento acerca do tema proposto. Embora no decorrer do texto, houve a verificação de que o entendimento dos autores utilizados não foi divergente, cada conceituação e opinião a seu modo, todos foram necessários e suficientes para que na perspectiva do conhecimento tenha ocorrido a contribuição deste conteúdo.

No primeiro capítulo, enfatizou-se quanto à definição do Direito das Sucessões, seu histórico, a conceituação dos autores estudados, e os diversos tópicos acerca da sucessão, fato que sintetiza o assunto a ser tratado no decorrer de todo trabalho.

O segundo capítulo se desempenhou através do inventário e a partilha em si, demonstrando-se, as espécies de inventário, como é o procedimento a ser desencadeado, motivo pelo qual responde a uma das perguntas enunciadas ao introduzir este.

No entanto, evidencia-se no referido capítulo, a explicação e resolução de outro questionamento, referente à diferenciação entre o inventário judicial e o extrajudicial, interessante notar cada requisito, pois para os herdeiros que infelizmente sofrem com a perda de seu ente querido, no Direito, denominado "de cujus", e precisam se valer do inventário, há que se observar quanto às espécies de inventário, para que seja feita a apreciação e decisão quanto ao mais benéfico, e em conta. Motivo este, que influenciou drasticamente a intensa pesquisa ao assunto, e concluiu-se que no inventário extrajudicial, além de célere, é menos burocrático.

É válido enaltecer também quanto ao terceiro capítulo que, por se tratar do último item, possui maior conteúdo a ser demonstrado, respondendo então à pergunta referente aos procedimentos para a realização do inventário e partilha itens esmiuçados no capítulo em questão, conceitua o arrolamento como um todo, suas espécies; trata acerca do imposto a ser pago para que seja feita a partilha; além de expor a opinião dos autores estudados a respeito do inventário.

Ao finalizar este trabalho de conclusão de curso, percebe-se que o saber quanto às noções de inventário, partilha e os demais tópicos tornaram-se mais claros e sucintos. O que antes era dificultoso, agora está exposto com maior exatidão, a magnitude deste conteúdo para o mundo jurídico é de grande valia, pois é uma forma de proteger o patrimônio que, por ser um direito, faz-se necessário estar regularizado conforme a lei dispõe. Como também, é útil pois poderse-á ser utilizado a título de conhecimento e informação aos que se interessem ou necessitem.

A compreensão do termo retro citado foi pautado através do Código Civil, da Lei 11.441/2007, e nas doutrinas, pelo qual os doutrinadores se esforçam a discorrer sobre o tema. Faz-se necessário salientar a importância do tema no cotidiano das pessoas que passam pela perda de um ente querido, mesmo com tamanho sofrimento, há que regularizar a situação do patrimônio deixado pelo de cujus.

Abordou-se com afinco quanto ao inventário realizado nos cartórios extrajudiciais, a ênfase se deu através da facilidade e praticidade em se proceder com o mesmo e além do mais, a respeito do baixo custo envolvido no procedimento especificado.

Vê-se de suma importância especificar que não são em todos os casos em que o inventário extrajudicial 
poder-se-á ser utilizado, pois quando houver herdeiros incapazes e/ou conflitos entre os interessados, por exemplo, dever-se-á recorrer ao inventário judicial.

Diante de todo exposto, pode-se entender que não há apenas uma forma de se efetuar o inventário, o ideal é situar-se e fazer a análise das hipóteses e em qual tipo será melhor enquadrado.

É de importante conhecimento, que somente a morte pode fazer nascer o direito hereditário, das sucessões, pois é um modo de substituir os bens do de cujus às pessoas, pelo qual são denominadas de herdeiros ou até mesmo sucessores.

\section{REFERÊNCIAS}

BRASIL. Lei no 11.441, de 04 de Janeiro de 2007. Brasília: Presidência da República do Brasil. Disponível em: <http://www.planalto.gov.br/ccivil_03/_ato20 07-2010/2007/lei/111441.htm>. Acesso em 29 de Janeiro de 2018.

CAHALI, Francisco José; HIRONAKA, Giselda Maria Fernandes Novaes. Curso avançado de direito civil: Direito das Sucessões, v. 6. $2^{\mathrm{a}}$ ed. São Paulo: Revista dos Tribunais, 2003.

DINIZ, Maria H. Curso de direito civil brasileiro: direito das sucessões. 28. ed. São Paulo: Saraiva, 2014. v. 6

FIUZA, César. Direito civil: curso completo. 17 ed.São Paulo: Editora Revista dos Tribunais; Belo Horizonte: Del Rey Editora, 2014.
GIANCOLI, Brunno Pandori. Direito Civil. São Paulo: Revista dos Tribunais, 2012. Coleção elementos do direito; v. 4

GOMES, Orlando. Sucessões. 14. ed. Rio de Janeiro: Forense, 2008.

GONÇALVES, Carlos Roberto. Direito civil brasileiro, volume 7: direito das sucessões / Carlos Roberto Gonçalves. - 11. Ed. - São Paulo : Saraiva, 2017.

GONÇALVES, Marcus Vinicius Rios. Inventário Novo CPC (Lei no 13.105/15). Direito Net, 19 de Março de 2009. Disponível em: <https://www.direitonet.com.br/resumos/exib ir/423/Inventario-Novo-CPC-Lei-no-1310515>. Acesso em 27 de Janeiro de 2018.

LISBOA, Roberto Senise. Manual de Direito Civil: direito de família e sucessões. 8. ed. São Paulo: Saraiva, 2013. v. 5.

MONTEIRO, Washington B. Curso de direito civil: direito das sucessões. 37. ed. São Paulo: Saraiva, 2009. v. 6

PEREIRA, Caio Mário. S. Instituições de Direito Civil. 21. ed. Rio de Janeiro: Forense, 2014.

RIZZARDO, Arnaldo. Direito das Sucessões. 8. ed. Rio de Janeiro: Forense, 2014.

RIZZARDO, Arnaldo. Direito das Sucessões. 5. ed. Rio de Janeiro: Forense, 2009. Lei no 10.406, de 10.01.2002.

VENOSA, Sílvio de Salvo. Direito civil: direito das sucessões. 14. ed. - São Paulo: Atlas, 2014. v. 7.

WALD, Arnoldo. Direito Civil: direito das sucessões, vol. 6. 14. ed. São Paulo: Saraiva, 2009. 